\title{
The Core Value and Moral Codes in Laoist Politics
}

\author{
Yajun $\mathrm{Wu}^{1,2^{*}}$, Xia Kang ${ }^{3}$ \\ ${ }^{1}$ College of International Studies, Southwest University, Chongqing, China \\ ${ }^{2}$ School of Foreign Languages and Literature, Yunnan Normal University, Kunming, China \\ ${ }^{3}$ Faculty of Education, The University of Hong Kong, Hong Kong, China \\ Email: *wuyajun1225@163.com
}

How to cite this paper: Wu, Y. J., \& Kang, X. (2019). The Core Value and Moral Codes in Laoist Politics. Chinese Studies, 8 , 67-82.

https://doi.org/10.4236/chnstd.2019.83006

Received: July 10, 2019

Accepted: August 20, 2019

Published: August 23, 2019

Copyright (c) 2019 by author(s) and Scientific Research Publishing Inc. This work is licensed under the Creative Commons Attribution International License (CC BY 4.0).

http://creativecommons.org/licenses/by/4.0/

\begin{abstract}
The core value and moral codes in Laoist politics are the essential factors that mold the political ethics in the Eastern Asia. In this study, the notion of "ziran" (self-thus-ness) was explored from four perspectives: its literal meaning, its five uses, the position of ziran in Laozi's political thoughts, and the perspective of the target readers of the Dao De Jing (DDJ). We argue that ziran is a highly regarded value in Laoist politics. More precisely, the maintenance of the common people in their self-thus-ness should be the ultimate goal of rulers. Based on this, we asked how this core value can be realized in the process of governing a state. To respond to this question, we applied content analysis and expound the four moral codes that the rulers ought to embrace.
\end{abstract}

\section{Keywords}

Core Value, Moral Codes, Dao De Jing, Ziran, Laoist Politics

\section{Introduction}

The virtues in the Dao De Jing (DDJ) have been extensively studied and practiced for well over 2500 years by all sorts of people, playing an important role in the progress of East Asian social civilization. The core values and moral codes that are highly praised in the DDJ still have enlightening significance for today's political ethics. As noted by Yan, 2009 (p. 173), "the Daodejing has much relevance to contemporary moral philosophy, especially in relation to virtue ethics". Similar views are held by other DDJ researchers like Ames, Ivanhoe, and Moeller (Ames, 1989; Ivanhoe, 1999; Moeller, 2006). Ames (1989) stated that the term of "de" is about "how to transform content and disposition of an existence", and further argued that the term de in the Laoist philosophical system has been "se- 
verely undervalued" (Ames, 1989: p. 124). Along this vein, Ivanhoe (1999: p. 240) argued that the term de in the DDJ is an ethical concept that takes on "a genuinely ethical sense". Moeller (2006: p. 13) emphasized the practical aspects of de and rightly states that "they are lessons for acting and behaving, and they are learning materials for strategic training". The cultivation of sage-rulers takes de as the watershed, that is, an ideal ruler must be a person with de.

De is of importance in cultivating a sage-leader; however, the connotation of de is varied and controversial (Cline, 2004: p. 219). It seems to be a consensus among DDJ authorities that de is a core concept of the DDJ (Ames, 1989; Cline, 2004; Ivanhoe, 1999; Moeller, 2006; Wagner, 2003). However, other scholars (e.g. Lau, 1963) have taken the opposite view, that de "is not particularly important" (Lau, 1963: p. 42). The divergence and dispute in interpreting the term de are generally manifested in two aspects: de as a metaphysical concept and that the moral codes of the DDJ should be discussed metaphysically; and de as a particular concept that concerns virtue theory (Zhou, 2006: p. 86). Cline (2004) discussed the connotation of de in a metaphysical domain and misleadingly interpreted it as "virtue". In contrast, other scholars view de as a particular notion and focus on the adequacy conditions for the generation of a thing or an affair.

The premise to observe the role of de in Laoist politics is to identify and clarify its value and orientation in the text of the DDJ. The leading cause for the inconsistency in understanding de is that its core value as well as the moral codes used to realize the core value has not been systemically explored in the existing studies. Thus, we aimed to identify the core value in Laoist politics and clarify the moral codes related to the practice of this value. The paper is significant for two reasons: we clarify the connotations and philosophical implications of de and the role of moral authority in governance is also discussed.

\section{The Core Value in the Text of the DDJ}

The writing purposes of the DDJ will help in the exploration of the core value and the understanding of the connotations of the core value in Laoist politics, but contrary to our expectations, this topic has seldom been discussed. Therefore, it was necessary to explore the writing purposes of the DDJ before discussing the significance of de in cultivating a sage-leader. The notion of "ziran" ("self-thus-ness") embodies the intrinsic requirements of de, that is, the sage-leaders are rulers that possess the virtue of de, and they take ziran as the guidelines for their behavior. In this section, the core value as well as the writing purposes of the DDJ are explored from four perspectives: 1) the literal meaning of ziran ("nature" or "self-thus-ness"), 2) the five uses of ziran in the text of the DDJ, 3) the position of ziran in Laozi's thoughts, and 4) the perspective of target readers of the text of the DDJ.

\subsection{Literal Meaning of Ziran}

The term ziran represents the core value of Laozi's political ideology (Dong, 
2014; Krueger, 2009; Liu, 1999), but the interpretation of its meaning is controversial. Part of the reason for this, as argued by Liu, is that "it is... rather difficult to describe or analyze ziran with any sort of precision" (Liu, 1999: p. 213). However, consideration of the literal meaning of ziran was our first step in exploring the implications of the core value in Laoist politics. The term ziran was first used in the DDJ and the interpretation of its meaning is not unified, as it does not appear in any earlier or contemporaneous documents from Laozi's era. The two representative ways of interpreting the term ziran are to think of it as a single-morpheme word and to think of it as the combination of two Chinese characters. Some scholars (Chan, 1963; Lau, 1963; Schwartz, 1985) hold a naturalistic interpretation in the sense that ziran is read as a single-morpheme word that means "nature". On the contrary, Lai (2007) noted that ziran "derives, in part, from a literal combination of its two terms, 'zi' and 'ran'” (Lai, 2007: p. 330).

"Zi" and "ran" are the two components of ziran and these two words' meanings in ancient Chinese philosophical texts help us to understand the literal meaning of ziran. Zi is derived from "bi" ("nose"); zi takes on the same meaning as nose (Duan, 1982: p. 136). Ancient Chinese people believed the nose to be the first organ to develop in a human embryo, so the nose signifies the very beginning of a human being and it takes on the sense of "the beginning". That is, the meaning of $\mathrm{zi}$ is "the beginning". According to the appended dictionary commentary to the meaning of the archaic Chinese characters, the earliest Chinese encyclopedia dictionary interprets ran as "cheng" (Ruan, 1982: p. 483). Cheng denotes the existential state and the developing process of something; that is, cheng means the "realization" and "come into being" of a thing or an affair. This signifies that ran has close connections with reality and denotes the creation process of something. Together, the literal meaning of ziran is the creation of something (ran) according to its initial law (zi). Lai emphasized the intrinsic property of this term and translated it as "spontaneity" (Lai, 2007: p. 332). Spontaneity cannot completely describe the meaning of ziran, but the spontaneous aspect captures the essence of this term. We see this, for example, in chapter 17 of the DDJ: “The hundred families' achievements are completed and affairs are followed through, a hundred families all say 'we are like this (i.e. have this bountiful life) spontaneously"' (trans. Wagner, 2003: p. 175).

The sentence "wo ziran" ("we are like this spontaneously") in the above paragraph has three implications. Common people live a bountiful life and they ascribe this to their own nature rather than the rulers' interventions. Thus, it can be seen that ziran includes a sense of spontaneity. The character "wo" ("we") in the sentence wo zi ran contains a sense of selfness, which implies that ziran does not contain the sense of selfness; otherwise, semantic repetition may occur in the sentence wo zi ran. Syntactically, wo (we) is the nominal subject of the sentence wo zi ran, which implies that ziran is best not understood indiscriminately as "nature", because the syntactic configuration of "noun plus noun" is unacceptable in Chinese language. Even though the term ziran is interpreted as nature, as 
determined by Lai (2007), "we need to explain how we might interpret "nature"” (Lai, 2007: p. 329).

Based on the above analysis, we translate the term of ziran into self-thus-ness, and it is not acceptable to translate it into "nature". Both the sense of "the beginning" that is derived from "zi" and the sense of "creation" that is derived from "ran" are embodied in the concept of "self-thus-ness". If the literal meaning of ziran is interpreted as "nature", we have to explore the connotations of "nature" further. More importantly, the sense of "the beginning" and "creation" cannot be covered by "nature".

\subsection{The Five Uses of the Term of Ziran in the Text of the DDJ}

The argumentative mode in the text of the DDJ is conducive to better understanding the writing purposes of the DDJ. The argumentative mode facilitates the grasping of the connotations of ziran. Most scholars do not accept the view that Laozi advocates an "environmentalist position" (Cooper, 1994; Liu, 1999), but this does not mean that we no longer need to learn from nature. Laozi, the acknowledged author of the DDJ, selected several images, such as water, vale, and uncarved block from nature, to present his intended purpose. The metaphor is a frequently-used tool in ancient Chinese texts as it has strong persuasive value ( $\mathrm{Lu}, 2002:$ p. 108). As argued by Chen and Holt (2002), the purpose of the DDJ is "to reform society to research an ideal state" (Chen \& Holt, 2002: p. 167). Instead of delivering this purpose directly, Laozi resorted to natural images to "transform meanings of dao from the metaphysical level to social-behavioral levels" (Chen \& Holt, 2002: p. 153). The images selected in nature provide the "ontological basis" (Fried, 2012: p. 421) for understanding the measure of truth in the social realm. Cheung (2017) denied the possibility of descriptively naming the metaphysical concept, as it "runs against the limits of language" (Cheung, 2017: p. 365). As Xiao (2002) correctly stated, "negation, paradox, and analogy/metaphors" are three repeatedly used rhetorical tools in ancient Chinese writings (Xiao, 2002: p. 139). It appears that Laozi tends to believe in the expressive power of metaphor (Nuyen, 1995: p. 495). Let us consider the following passage from the Appended Words commentary to the Classic of Changes, a canonical Confucian exegesis, which brought what had been a divination text into the realm of philosophical discussion: "The heaven overhangs various phenomena, the earth gives form to a myriad of things, and this is known as change. And thereupon, the sage comprehends the truth by emulating these changes" (Jin, 1998: p. 89).

Natural phenomena represent effective media to reveal truth in the social realm. By analyzing the text of the DDJ, for example, water occurs several times (e.g. chapters 8 and 66) to reveal the nature of "dao" (Chan, 1963: p. 113). In addition, Chen and Holt (2002) noted that "symbolic use...can be a tool to increase the effectiveness of rhetorical persuasion" (Chen \& Holt, 2002: p. 155). To summarize, the metaphor is an effective vehicle to enable the metaphysical concepts in the text of the DDJ to be nameable and understandable. Additionally, the 
purpose of describing the characteristics of things in nature is to clearly elucidate truth in society.

In total, there are five uses of ziran in the text of the DDJ (chapter 17, 23, 25, $51,64)$, and it is believed that the implications of this concept can be clarified through content analysis of these five uses. The term ziran first appears in chapter 17 of the DDJ. In this chapter, the common people claim that they have a bountiful life purely as a result of their own nature. In other words, the common people can make a good living on their own, and there will be no such good life if the rulers interfere. The other four uses of ziran appear in chapters $23,25,51$, and 64 of the DDJ. In chapter 23, Laozi argues that the method to practice the values of ziran is to speak little. Observations outlined by Chen (1984) remind us of the correlation between "speak little" in chapter 23 with "teaching without words" in chapter 2 (Chen, 1984: p. 157). The rulers are recommended to issue as few orders as possible to allow the common people to be transformed of their own accord. Chapter 25 of the DDJ reads, "dao patterns itself after ziran". The main point of this sentence is that dao (the metaphysical concept that denotes the ways) embodies nature. Chapter 51 of the DDJ reads, "without anyone's order, dao is honored and de is valued for they obey the principle of ziran". Dao denotes the ontological basis for the creation of all creatures, and de nourishes the development of all creatures, but both dao and de observe the guidelines of ziran. Chapter 64 of the DDJ reads, "the sage-rulers do some ancillary work without any interference with the creatures' nature; thus, all creatures can develop according to their initial law". The guidelines of ziran represent moral authority in governance, that is, rulers are suggested to not disturb the quiet life of common people.

\subsection{Embodiment of Ziran in the Particular Thoughts of the DDJ}

Determination of the position of ziran in the particular thoughts of the DDJ will provide understanding about the core value of the DDJ. Contrary to Moeller (2006)'s arguments that DDJ "lacks an author, a clearly stated topic, and a beginning and end" (Moeller, 2006: p. 4) and that the DDJ can be explored from "any chapter or verse" (Moeller, 2006: p. 6), we argue that the term ziran is the cohesive point from which to elaborate the specific thoughts in the text of the DDJ. If this is the case, then we further demonstrate that ziran embodies the core value of the DDJ. In this section, five specific thoughts of the DDJ are discussed with textual evidence to support the argument that the specific thoughts are demonstrated with ziran as the core value. More precisely, the notion of de, political thoughts, military thoughts, thoughts of the ideal society, and the values of life that are argued for in the text of the DDJ take ziran as the guideline.

\subsubsection{Ziran in the Understanding of De}

De is indispensable to a sage-ruler, and the thought of de is presented in chapter 38 of the DDJ: "A man of high virtue does not claim he has virtue, so he is vir- 
tuous. A man of low virtue claims he has not lost virtue, so he is virtueless. A man of high virtue does nothing on purpose; a man of low virtue does nothing without purpose" (trans. Xu, 2013: p. 53).

In the context of the DDJ, the highly recommended virtue to a sage-ruler is de. "A man of high virtue does nothing on purpose" means that the virtuous rulers will not disturb the common people for they possess no ulterior motives. The Collection of Laws and Institutions in Ancient China, an important material for studying the society in the pre-Qin period defines de as "yu" n ("givingness") (Ruan, 1982: p. 1431). The sense of givingness in terms of de indicates that sage-rulers should be public-spirited in their governance. In other words, the requirement of de for rulers means that rulers are required to leave the common people in their natural state (ziran).

\subsubsection{The Embodiment of Ziran in Political Thoughts}

Chapter 60 of the DDJ offers a short sketch of the ideal policy and the leadership required to govern a state: "In ruling a big state, the sage-ruler acts as if they are frying a small fish". Additionally, a more detailed description of political thoughts is stated in chapter 58 of the DDJ, "If a ruler who regulates the government without intruding upon people's internal affairs, then the people will be gentle and candid; if a ruler who regulates the government severely disturbs people's spontaneous state, then the people will feel uneasy".

These two passages argue that the Laoist political thoughts also take ziran as the guideline. As pointed out by Chen and Holt (2002), in governing a state, the rulers' purposeful actions are unnecessary for the reason that "their purposeful actions are contrary to the natural course of the universe, bringing harm and leading to disaster" (Chen \& Holt, 2002: p. 160). Chapter 57 of the DDJ argues that "to rule with no severe law will be able to rally all the people under heaven". That is, unnecessary administrative intervention should be minimized as it disturbs the common people's spontaneous state (ziran). To conclude, the political thoughts in the DDJ place strict restraints on the rulers' interventions, which reflects the value of ziran.

\subsubsection{The Embodiment of Ziran in Military Thoughts}

The anti-war ideology is clearly manifested in chapter 30 of the DDJ: "Where goes the army, only briars and thorns will grow. After a great war comes a year of famine".

War brings suffering to common people, and their natural state will be inevitably broken by war. However, the necessity of a just war is not denied in the DDJ. As stated in chapter 31 of the DDJ, "when the rulers have no alternatives but to take part in a war, the rulers should take it by surprise". The rulers are suggested to end a war as soon as possible, even if it is a just war. The underlying reasons for these two arguments reflect the people-oriented nature of the thought, that is, rulers should try not to disturb the common people's natural state. Therefore, it can be concluded that the military thoughts in the DDJ reflect 
the value of ziran.

\subsubsection{The Embodiment of Ziran in the Thoughts of Ideal Society}

Chapter 80 of the DDJ presents us with an ideal social model, with a minor revision of Xu's translation:

The rulers value their people's lives and try to avoid their people migrating far away. Even if they have ships and carriages, they do not need to ride; even if they have armors and weapons, they do not need to use them. The rulers assist their people in returning to the age of recording by knotting cords. People will find their food delicious, their clothes beautiful, their houses comfortable, and their local customs delightful (trans. Xu, 2013: p. 97).

As described above, in the DDJ, the ideal society refers to a society with no aggregation, no oppression, and no interference from the outside and no exploitation, turmoil, or fraud from the inside. To realize an ideal society, rulers should follow the principles of ziran. "To avoid the common people from migrating far away" and "to return the common people to the age of recording by knotting cords" are the two measures used to maintain the common people in their natural state (ziran). Once again, the values of ziran are reflected and emphasized in building an ideal society.

\subsubsection{The Embodiment of Ziran in the Value of Life}

The value of life in the DDJ is argued in chapters 19, 37, and 46. Chapter 19 states that "people should manifest simplicity and embrace the unadorned; reducing the selfishness and avoiding desires". A similar value of life is also expressed in chapter 46, "no crime is greater than insatiable desire, and no calamity is greater than discontentment". The insatiable value of life is criticized in chapter 37, which states that a peaceful life for the rulers and tranquility in society can be expected only if the rulers have overcome their selfishness and have controlled their insatiable desires. As Steinberger (1989) persuasively argued, "humans... are apt to multiply their desires far beyond what is natural and necessary" (Steinberger, 1989: p. 1210). The rulers' insatiable desires are a factor that would bring disaster to common people. For instance, rulers' desires for gorgeous clothes, rare treasures, tasty food, and fabulous fortune (chapter 53 of the DDJ) will inevitably throw common people into "poverty and chaos" (chapter 57 of the DDJ). That is, rulers' desires that "exceed what is necessary for their existence" (Duncan \& Steinberger, 1990: p. 1319) should be curbed; otherwise, the common people can no longer remain in a peaceful and spontaneous state. Based on the analysis above, we conclude that the value of life should be guided by the principles of ziran.

To summarize, our claim, as has been demonstrated above, is that the values of ziran are highly advocated in the other five specific types of thought. In understanding de, political thoughts, military thoughts, the thoughts of ideal society, and the value of life should take the value of ziran as the guideline. The self-thus-ness of the myriad of things in nature and the self-thus-ness in the social realm are all highly valued in the text of the DDJ. This provides strong rea- 
son, we think, to accept that the term of ziran embodies the core value in the Laoist philosophical system.

\subsection{Target Readers of the DDJ}

The perspective of the target readers will also help explain the writing purposesof the DDJ, but this has not been addressed clearly in existing studies. There are generally two views on the target readers of the DDJ. Some researchers (e.g. Chan, 1963; Lai, 2007) hold that the common people are the target readers of the DDJ because anyone reading the text of the DDJ can be inspired. Others (Heilbrunn, 2009; Moeller, 2006) hold the opinion that the core of the theme in the DDJ is leadership qualities, meaning the rulers are the target readers. Several researchers discussed the relationship between "dao" ("the way") and the art of leadership, which indicates that the target readers of the DDJ are rulers. LaFargue (1994) argued that the main theme of the DDJ is leadership and that "the spirit of dao informs governmental policy and leadership style" (LaFargue, 1994: p. 219). In discussing the nature of dao, Ames (1994) stated that the text of the DDJ is about "Laoist political theory" (Ames, 1994: p. 42). Moeller (2006) discussed the social context of Laozi's time and held the opinion that "Daodejing was transmitted from mouth to mouth within a cultural elite... was used by this group as guideline for the exercise of social power" (Moeller, 2006: p. 2). In Heilbrunn's words, "the dao... is employed as a mean to help sustain authority" (Heilbrunn, 2009: p. 83). In conclusion, the analysis of the target readers and the exploration of the connotations of ziran provide solid evidence, we think, that the purpose of the DDJ is to end social turbulence, and exercising the values of ziran is a concrete measure that can be taken by the rulers to achieve this purpose.

The term "Laoist sage-leaders" bears a high similarity to Platonic philosopher-kings; thus, it is expected that the connotations of Laoist sage-rulers can be obtained by contrasting them with those of Platonic philosopher-kings. Facing social confusion, Laozi was committed to restoring social order by improving the rulers' leadership qualities. Similarly, Platonic philosophy involves a quest for "some better political arrangement for city-state" (Pappas, 2003: p. 3)—Plato also concentrated his efforts on restoring the social order of his time and pinned his hopes on the cultivation of philosopher-kings. The term "philosopher-kings" was first coined in The Republic and refers, in Plato's words, to the idea that:

Philosophers are kings or the kings and princes of this world have the spirit and power of philosophy, and political greatness and wisdom meet in one, and those commoner natures who pursue either to the exclusion of the other are compelled to stand aside, cities will never have rest from their evils (Plato, 2003: p. 226).

Philosopher-kings are vital in the process of restructuring a "feverish city" to a "just city" (Steinberger, 1989: p. 1210) because they have, in comparison with the guardians, "genuine knowledge of the truth" (Steinberger, 1989: p. 1215). 
Even though the importance of ziran in the text of the DDJ has been highly emphasized and its connotations were also explored in the above analysis, it is not clear how to implement them in the cultivation of sage-like rulers. By analyzing the embodiment of ziran in the particular thoughts and five uses in the text of the DDJ, we concluded that ziran is the core value of the DDJ. The literal meaning and the target readers of the DDJ were also explored to clarify the connotations of this core value. As noted by Chen and Holt (2002), the aim "to reach an ideal society" is inseparable from the cultivation of rulers (Chen \& Holt, 2002: p. 158). Laozi placed his hopes on the cultivation of sage-rulers to turn chaotic society into an ideal society in which the common people can live a bountiful life. In the text of the DDJ, a variety of moral codes are advanced to cultivate the sage-like leaders; however, both the moral codes and the methods to implement these moral codes in the cultivation of sage-leaders are not without controversy. The core value of the DDJ charts the orientation for the exploration and explanation of the moral codes in the DDJ. Therefore, in the next section, the moral codes for the cultivation of the sage-leaders are explored under the premise of the core value.

\section{Moral Codes for the Cultivation of the Sage-Leaders}

The moral codes set out in the text of the DDJ are targeted at the rulers, and the explorations of these moral codes have significance in two areas. The rulers in Laoist politics play two polar opposite roles in the process of constructing an ideal society. One of them is that the rulers are the source of disasters. For example, as argued in the DDJ text, if the rulers are insatiable for power, wealth, or rare goods, the common people would be forced into war and would be likely to become destitute. The other one is that to restore social order, in Laozi's view, the power of the rulers needs to be relied upon. The moral codes that are advocated in the text of the DDJ are significant in two ways: to gain a clear idea of how such moral authority in Laoist politics might be derived from paying subtle attention to the actualities of the physical and social worlds; and the moral authority in modern governance can gain enlightenment from the moral codes in the text of the DDJ.

It is argued that the term "dao" in the text of the DDJ embodies the ontological basis for the creation of all things, including the moral codes. As claimed by Ames (1994), "any discussion of the Daodejing must begin from an explication of this concept" (Ames, 1994: p. 33). More importantly, Laozi sets out the criteria for being a sage-leader in chapter 8 of the DDJ, "a sage-leader is the one who comes close to the dao" (chapter 8). Thus, investigation of the moral codes through exploring the nature of dao is expected. For centuries, numerous scholars have devoted their efforts to studying the connotations and the nature of dao, but regretfully, as argued by Cheung, the attempt to describe the "constituent aspectual totalities of dao is futile" (Cheung, 2017: p. 369). The limits of language determine that it is impossible to completely describe the "unsummed to- 
tality" of dao (Cheung, 2017: p. 352). In other words, it is challenging to clarify the moral codes by clarifying the connotations of dao.

To respond to this challenge, we argue that the moral codes for the cultivation of sage-leaders in the text of the DDJ can be explored through text analysis. Nuyen (2000) stated that "the secrets of the dao can be accessed through the accomplishment of the de" (Nuyen, 2000: p. 293). Those rulers whose behaviors conform to the requirements of the de are ideal rulers in Laoist politics, and it is expected that moral codes will be obtained by observing these rulers' behaviors. We agree with $\mathrm{Lu}$ (2002) that "the use of moralistic language is the central feature of Chinese politics" (Lu, 2002: p. 106), which means that the exploration of moral codes should be based on a content analysis of the DDJ.

According to Laozi's definition, sage-rulers are those who act in agreement with the connotations of de. In the following section, the connotations of de are discussed using four conceptual schemes to explore the moral codes. The four conceptual schemes are "wusi", "wuyu", "buzheng", and "weierbushi". These four moral modes have long been highly recommended by Daoism (Fan, 2000). However, these four moral modes are consistent with the intrinsic requirements of ziran. The textual evidence also indicates that the explanations of de should be conducted inside these four related dimensions. For these reasons, to comprehensively understand the moral codes, it is necessary to work through these four conceptual schemes with reference to the DDJ.

\subsection{The Moral Code of "Wusi"}

The first requirement for rulers in the Laoist politics is to be selfless ("wusi"). As we will see, considerable textual evidence supports the importance of wusi in the cultivation of a sage-like ruler. For example, chapter 7 of the DDJ states, "the sage disregards his safety and then his safety can be guaranteed". Similarly, chapter 13 of the DDJ indicates that "we will suffer the disaster because we have a body; if we forgot about our bodies, what disaster would there be for us?" These two statements emphasize that rulers need to forgo their own interests to better govern the common people.

Instead of being a selfish person, the sage-ruler should be selfless and perform in accordance with the core value of ziran. The core value of ziran to the common people is that the common people can live a bountiful life and will not be disturbed by their rulers. The selfless sage-rulers do not disturb the common people for their own interest, and it is believed that "the common people can live a life of abundance on their own" (chapter 57). Therefore, the moral code of wusi is important in the cultivation of a sage-like ruler.

The moral code of wusi (without considering one's own interests) conforms to the core value of ziran, and the in-depth connotations of wusi can be elucidated within this core value. Firstly, the selfish behaviors of the rulers are explicitly denied in the text of the DDJ. For example, chapter 72 of the DDJ denies the necessity of the reputation of a sage-like ruler, stating that rulers need to "know themselves but it is unnecessary to show off themselves (even if they did some- 
thing good for the common people); cherish themselves but they should not overvalue themselves" (chapter 72). Besides, rare goods, such as rhinoceros products, and extravagant demands, such as gorgeous clothes, keen-edged swords, and delicacies, are also obstacles to developing into a sage-ruler. The selfishness of the rulers may bring disaster to the common people. If the common people are forced to collect rare goods for the rulers or if they have to do heavy labor to adhere to the rulers' vanity, then the natural and spontaneous state (ziran) of the common people will be destroyed. Therefore, as argued above, reputation and extravagant demands are both unnecessary for a sage-ruler, because sage-rulers are selfless people, and it is not acceptable for them to break down the natural and spontaneous state of the common people. If so, as argued in chapter 50 of the DDJ, "the rhinoceros have no use of their horns, and tigers of their claws, and swords of their blades, then the common people will not come near to death" (chapter 50). Only if the rulers observe the moral code of wusi can the core value of ziran remain unviolated.

\subsection{The Moral Code of "Wuyu"}

The second requirement for rulers in Laoist politics is to be unambitious ("wuyu"). The importance of wuyu to rulers is emphasized in many chapters of the DDJ. As stated in chapter 12 of the DDJ, "the sage-ruler is for belly but not for eyes", which implies that rare goods or extravagant demands should be abandoned. In chapter 46 of the DDJ, the rulers' desires are denied because "there is no greater crime than rulers who show their desires and there is no greater calamity than rulers who do not know how to be satisfied". These two statements argue that rulers should impose strict controls over their desires or ambitions.

The moral code of wuyu (unambitious) also embodies the core value of ziran, and the connotations of wuyu can be explored in accordance with this core value. At the end of the spring and autumn periods, various feudatory states were attached to each other and the common people were forced to take part in wars. The cause of the successive wars was also exposed in the text of the DDJ. The rulers' ambitions were denied in chapter 29 of the DDJ, which states that "those who desire to conquer the world cannot succeed according to their ambitions" (chapter 29). Unfortunately, as described in chapter 61 of the DDJ, "the big feudatory states wish to annex the small feudatory states and the small feudatory states also dream to absorb the big state" (chapter 61). The harmfulness of the rulers' desires is stated in chapter 46 of the DDJ, "there is no greater sin than the desire of possession" (chapter 46). It can be said that war is closely connected with the ambitions of rulers. With the core values of ziran in mind, the natural and spontaneous state of the common people will be disturbed if the rulers force them to engage in a war or collect extravagant goods to satisfy their desires. That is, it is not possible for the common people to maintain their natural and spontaneous state if their rulers are insatiable. The moral code of wuyu means that the rulers restrain their desires and ambitions so that the natural and spontane- 
ous state (ziran) of the common people is not disturbed.

"Zhizu" and "zhizhan" are two approaches used to restrict the ambitions and desires of rulers. Laozi provided two practical methods for the rulers to control their excessive desires. The relationship between contentment and desire is, as argued by Chen and Holt (2002), that "contentment is the principal way to reduce desire" (Chen \& Holt, 2002: p. 161). Rulers should be people who can be easily satisfied ("zhizu"). The merit of zhizu (to be content with one's lot) has many benefits for rulers. In chapter 33 of the DDJ, Laozi argues that "a ruler would feel rich once they understand the significance of being an easily satisfied person" (chapter 33). Besides, as argued in chapter 44 of the DDJ, "a ruler would suffer no shame and would experience no danger when they know how to be satisfied" (chapter 44). "Zhizhan" (to eliminate war) is the other method used by rulers to restrict their ambitions. The anti-war ideology is expressed explicitly in chapter 30 of the DDJ, "the sage-rulers will oppose all conquest by force of arms because wherever the army goes, there are brambles and there will be years of crop failure after the great war" (chapter 30). A similar view is expressed in chapter 31 of the DDJ, "weapons are ominous objects that a man of noble character is forced to avoid" (chapter 31).

In other words, the moral code of wuyu for rulers requires rulers to restrict their ambitions and desires for the purpose of not disturbing the common people. Zhizu and zhizhan are the two methods used to implement the moral code of wuyu. It is believed that rulers' ambitions and desires are the reasons for them to launch wars. As a result, the common people are forced to engage in war and are forced to seek shelter in distant lands after the war. To avoid this miserable condition, zhizu and zhizhan have been proposed as methods to control rulers' ambitions and desires.

\subsection{The Moral Code of "Buzheng"}

The third requirement for the rulers in Laoist politics is to be noncompetitive ("buzheng"). The moral code of buzhen for the rulers, as argued in chapter 67 of the DDJ, is that "buzheng was one of the three treasures" (chapter 67). The term buzheng means that rulers should not be in competition with the common people for benefits. A similar opinion is argued in chapter 81 of the DDJ, "the way of being a sage-ruler is to do what they can do but not compete with the common people for benefits" (chapter 81). In Laozi's view, water has the virtue of noncompetitiveness, and the image of water can be used to elucidate the connotation of buzheng. Water has the merit of taking a lower position, as argued in chapter 66 of the DDJ, "water flows downwards and takes a lower position" (chapter 66). Water benefits a myriad of things in nature "even though it usually locates itself in the places that others dislike" (chapter 8). The rulers would be unmatched anywhere in the world if they learnt from water. As argued in chapter 73 of the DDJ, "it is the ways of Heaven that they who do not compete will win the battle" (chapter 73). In chapter 66 of the DDJ, it is argued that "no one can contend with the sage-ruler because they compete with no others" 
(chapter 66).

The moral code of buzheng embodies the core value of ziran, and the connotations of buzheng can be further explained under the guidance of this core value. The virtue of buzheng is illustrated in the form of examples in chapter 68 of the DDJ, "the skillful high-ranking commanders will not parade their superiority and strive to outshine others; the great rulers are not eager to compete but they finally conquer the enemy; these examples embody the virtue of buzheng and they are in keeping with the core value of ziran" (chapter 68). The battles among the feudatory states erupted frequently in Laozi's time. Laozi suggested that the moral code of buzheng is the solution to the social chaos caused by war, and he alerted rulers that those rulers who wantonly engage in military ventures will inevitably be defeated.

\subsection{The Moral Code of "Weierbushi"}

In line with Nuyen (2000) and most other DDJ researchers, we are inclined to treat the moral code of "weierbushi" (rendering services to the common people unobtrusively) as the fourth requirement for the rulers in Laoist politics. The term weierbushi is first mentioned in chapter 10 of the DDJ, "the highest virtue to a ruler is to benefit the common people without disturbing them" (chapter 10). Along the same vein, the moral code of weierbushi is emphasized again in chapter 51 of the DDJ, "the highest virtue to sage-leaders is that they perform their governing duties without disturbing or dominating the common people" (chapter 51). The water metaphor is commonly used to elucidate abstract notions (Chan, 1963; Chen \& Holt, 2002), and it has also been applied to explain the moral code of weierbushi. It is natural for water to flow downward, and many things benefit from water. However, Chen and Holt argued that water fulfills many functions in nourishing a myriad of things but it leaves no trace and will never take credit for its contribution (Chen \& Holt, 2002: p. 161). The moral code of weierbushi to the rulers requires them to render services to the common people without receiving payment from the common people.

The notion of "wuwei" contributes to our understanding of weierbushi; however, the interpretation of this notion is controversial. For example, Lai and many other scholars claimed that the notion of wuwei "essentially refrains rulers from coercive policies and practices" (Lai, 2007: p. 332), and its educative significance is "to get the rulers to do nothing" (Barbalet, 2011: p. 339). On the contrary, Nuyen attached a different meaning to the notion of wuwei. Nuyen reminded us that the notion of wuwei in Laoist politics does not signify that rulers should be "absolutely doing nothing" (Nuyen, 2000: p. 295). Instead, as stated by Laozi in chapter 17, "the rulers seem relaxed and seldom issue commands, and this is the way they accomplish their governing duties" (chapter 17). Liu insightfully identified two kinds of wuwei: "natural wuwei is better than intentional wuwei" (Liu, 1999: p. 226). Along this vein, Nuyen correctly stated that rulers should be actively involved in governing affairs but "not act out of some determinate interests" (Nuyen, 2000: p. 295). 
Therefore, we are inclined to recognize wuwei as the method to realize the moral code of weierbushi-the moral code of weierbushi requires rulers to be actively engaged in the governing of affairs but not for any ulterior motives. Even if rulers accomplish their duties without disturbing the common people, they should not take credit for them. As expressed in chapter 17, "with the rulers' endeavor, the common people's achievements are completed and their affairs are followed through, but the common people are not aware of the rulers' engagement and they say 'we are like this spontaneously"' (chapter 17).

\section{Conclusion}

The core value and the writing purposes of the text of the DDJ were first explored from four perspectives, and we concluded that ziran is the core value of Laoist politics: the political ideal in Laoist politics is that the common people can obtain and enjoy their natural and spontaneous state. In Laoist politics, the restoration of the ideal society from social chaos is highly dependent on the cultivation of sage-rulers, and four moral codes for the cultivation of sage-like rulers were also discussed in this paper. We argued that the moral codes of "wusi", "wuyu", "buzheng", and "weierbushi" are the four guidelines that should be observed by rulers in the process of governing a state. Rulers can regulate their own behaviors by observing these four moral codes, and the four moral codes are the guidelines for the rulers to restore a society that is full of war and poverty to an ideal society where the common people can independently live a bountiful life.

In Laoist politics, the four moral codes embody the core value of ziran, and the connotations of these four moral codes are further elucidated by the core value. Laoist politics reflect people-oriented thinking, specifically that the Laoist political ideal is that common people should stay away from wars and enjoy a bountiful life. The four moral codes are the practical methods used by rulers to implement the core value of the ziran when governing a state, and exploration of the connotations of these moral codes will be conducive to the improvement of rulers' governing quality. It is also hoped that the moral codes explored in this study can provide some inspiration to current leaders, especially when in terms of their relationships with common people.

\section{Author' Contributions}

Y.W., methodology, writing-original draft preparation; X.K., methodology, writing-review and editing.

\section{Acknowledgements}

This work was supported by the Fundamental Research Funds for the Central Universities (Grant number SWU1709442).

\section{Conflicts of Interest}

The authors declare no conflict of interest. 


\section{References}

Ames, R. T. (1989). Putting the Te Back into Taoism. In C. J. Baird, \& A. R. T. Albany (Eds.), Nature in Asian Traditions of Thought: Essays in Environmental Philosophy (pp. 113-44). New York: State University of New York Press.

Ames, R. T. (1994). The Art of Rulership: A Study of Ancient Chinese Political Thought. Albany, NY: State University of New York Press.

Barbalet, J. (2011). Market Relations as Wuwei: Daoist Concept in Analysis of China's Post-1978 Market Economy. Asian Studies Review, 35, 335-354. https://doi.org/10.1080/10357823.2011.602045

Chan, W. (1963). The Way of Lao Tzu. New York: The Bobbs-Merrill.

Chen, G. Y. (1984). Commentary on and Critical Introduction to the Laozi. Beijing: Zhonghua Shuju.

Chen, G.-M., \& Holt, G. R. (2002). Persuasion through the Water Metaphor in Daodejing. International Communication Studies, 11, 153-171.

Cheung, L. K. C. (2017). The Metaphysics and Unnamability of the Dao in the Daodejing and Wittgenstein. Philosophy East \& West, 67, 352-379. https://doi.org/10.1353/pew.2017.0030

Cline, E. M. (2004). Two Interpretations of De in the Daodejing. Journal of Chinese Philosophy, 31, 219-233. https://doi.org/10.1111/j.1540-6253.2004.00151.x

Cooper, D. E. (1994). Is Daoism “Green”? Asian Philosophy, 4, 119-125. https://doi.org/10.1080/09552369408575397

Dong, J. Q. (2014). On Laozi's Central Value. Social Science Front, 2, 26-31.

Duan, Y. (1982). Shuowen Lexicon. Shanghai: Shanghai Classics Publishing House.

Duncan, C. M., \& Steinberger, P. J. (1990). Plato's Paradox? Guardians and Philosopher-Kings. The American Political Science Review, 84, 1317-1322. https://doi.org/10.2307/1963266

Fan, Y. (2000). A Classification of Chinese Culture. Cross Cultural Management: An International Journal, 7, 3-10. https://doi.org/10.1108/13527600010797057

Fried, D. (2012). What's in a Dao? Ontology and Semiotics in Laozi and Zhuangzi. Dao, 11, 419-436. https://doi.org/10.1007/s11712-012-9290-1

Heilbrunn, D. (2009) Hermann Hesse and the Daodejing on the $\mathrm{Wu}$ and You of Sage-Leaders. Dao, 8, 79-93. https://doi.org/10.1007/s11712-008-9100-y

Ivanhoe, P. J. (1999). The Concept of de("Virtue") in the Laozi. In C. Mark, \& P. J. Ivanhoe (Eds.), Religious and Philosophical Aspects of the Laozi (pp. 239-257). Albany, NJ: State University of New York Press.

Jin, J. F. (1998). A New Edition and Detailed Interpretation on Xici of Zhouyi. Shenyang: Liaohai Publishing House.

Krueger, J. W. (2009). Knowing through the Body: The Daodejing and Dewey. Journal of Chinese Philosophy, 36, 31-52. https://doi.org/10.1111/j.1540-6253.2008.01503.x

LaFargue, M. (1994). Tao and Method: A Reasoned Approach to the Tao-te-Ching. Albany: State University of New York Press.

Lai, K. (2007). Ziran and Wuwei in the Daodejing: An Ethical Assessment. Dao, 6, 325-337. https://doi.org/10.1007/s11712-007-9019-8

Lau, D. C. (1963). Tao Te Ching. London: Penguin Books.

Liu, X. G. (1999). An Inquiry into the Core Value of Laozi's Philosophy. In C. Mark, \& P. J. Ivanhoe (Eds.), Religious and Philosophical Aspects of the Laozi (pp. 211-237). Al- 
bany: State University of New York Press.

Lu, X. (2002). Chinese Political Communication: Roots in Tradition and Impacts on Contemporary Chinese Thought and Culture. International Communication Studies, 11, 97-116.

Moeller, H.-G. (2006). The Philosophy of the Daodejing. New York: Columbia University Press.

Nuyen, A. T. (1995). Naming the Unnameable: The Being of the Tao. Journal of Chinese Philosophy, 22, 487-497. https://doi.org/10.1111/j.1540-6253.1995.tb00718.x

Nuyen, A. T. (2000). The Dao of Ethnics: From the Writings of Levinas to the Daodejing. Journal of Chinese Philosophy, 27, 287-298. https://doi.org/10.1111/0301-8121.00018

Pappas, N. (2003). Plato and the Republic (2nd ed.). London: Routledge.

Plato (2003). The Republic. Ontario: Share Books Publishing.

Ruan, Y. (1982). Exegetics of the Ancient Classics. Beijing: Zhonghua Book Company.

Schwartz, B. I. (1985). The World of Thought in Ancient China. Cambridge, MA: Harvard University Press.

Steinberger, P. J. (1989). Ruling: Guardians and Philosopher-Kings. The American Political Science Review, 83, 1207-1225. https://doi.org/10.2307/1961665

Wagner, R. G. (2003). A Chinese Reading of the Daodejing: Wang Bi's Commentary on the Laozi with Critical Text and Translation. Albany, NY: State University of New York Press.

Xiao, X. C. (2002). The Rhetorical Construction of the Discourse on the Dao in Daodejing. Intercultural Communication Studies, 11, 137-152.

Xu, Y. (2013). Laws Divine and Human. Beijing: Dolphin Books.

Yan, H. K. T. (2009). A Paradox of Virtue: The Daodejing on Virtue and Moral Philosophy. Philosophy East \& West, 59, 173-187. https://doi.org/10.1353/pew.0.0054

Zhou, H. C. (2006). The Concept of De in the Daodejing and the Ethics of Chinese Metaphysics. Studies in Ethics, 25, 86-91. 